Surgery Journal 5 (1): 7-8, 2010

ISSN: $1816-3211$

(C) Medwell Journals, 2010

\title{
Double Pylorus
}

Joye Varghese, Vallath Balakrishnan, Prem Nair and Venkadeswaran Anantha Narayanan Amrita Institute of Medical Sciences and Research Centre, Kochi, India

\section{CASE HISTORY}

A 73 years old man attended the outpatient clinic with vague abdomen pain. As he had recent episode of right sided hemiplegia, he was taking tablet aspirin $150 \mathrm{mg}$ daily for last 4 weeks. There was no history suggestive of hematemesis or melena. On examination, he was conscious and his vital signs were stable. Gastroscopy was done (Fig. 1).

\section{Question:}

What is the diagnosis?

Answer: Double pylorus or Gastroduodenal fistula.

\section{DOUBLE PYLORUS}

Double communications between gastric antrum and duodenal bulb is known as double pylorus. It is also known as epipyloric gastoduodenal fistula or antroduodenal fistula. It is an uncommon condition; $<100$ cases have been reported in literatures since the first case report on 1969 by Smith and Tuttle (1969) and Hegedus et al. (1978). As there is no specific gastrointestinal symptom due to double pylorus, most often it is diagnosed by gastroscopy while performing for other indications.

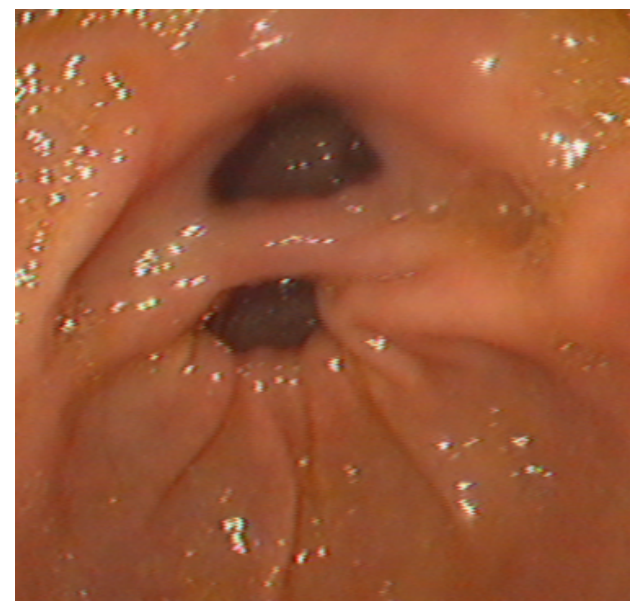

Fig. 1: Gastroduodenal fistula
Literatures reveal that its overall prevalence varies from $0.06-0.4 \%$ with male predominance (male:female ratio 2:1).

It is one of the consequences of peptic ulcer disease, particularly gastric ulcer rather than duodenal ulcer (Smith and Tuttle, 1969; Kothandaraman et al., 1983; Cappelletti et al., 1983).

Proposed mechanism for peptic ulcer induced double pylorus is perforation of underlying muscle layer by ulcer followed by fistula formation and re-epithelialisation (Kothandaraman et al., 1983).

Rohde et al. (1975) described this phenomenon by serial gastroscopy examinations in ulcer disease patients.

Association of helicobacter pylori has been observed as a case report series (Safatle-Ribeiro et al., 1999; Akazawa et al., 2005).

There are no reports regarding long-term complications of double pylorus. Even though, there is no specific medical therapy to asymptomatic double pylorus, those who has had gastric outlet obstruction by double pylorus, separation of mucosal bridge between the two openings by endoscopically using sphincterotome has successfully relieve gastric outlet obstruction symptoms (Graham et al., 1994).

\section{REFERENCES}

Akazawa, Y., Y. Mizuta, M. Osabe, T. Nakamura and S. Morikawa et al., 2005. A case of double pylorus caused by recurrent gastric ulcer: A long-term endoscopic observation. Dig. Dis. Sci., 50: 2125-2128.

Cappelletti, F., S. Recchia, L. Bonardi, M. Rizzetto and G. Verme, 1983. Gastroduodenal fistula complicating a prepyloric ulcer. Gastrointest. Endosc., 29: 111-113.

Graham, S.M., F. Lin and J.L. Flowers, 1994. Symptomatic double channel pylorus- successful treatment with biliary sphincterotome. Surg. Endosc., 8: 792-793.

Hegedus, V., P.E. Poulsen and J. Reichardt, 1978. The natural history of the double pylorus. Radiology, 126: $29-34$.

Corresponding Author: Joye Varghese, Department of Gastroenterology,

Amrita Institute of Medical Sciences and Research Centre, 682026 Kochi, India 
Kothandaraman, K.R., K.P. Kutty, K.A. Hawken and J.A. Barrowman, 1983. Double pylorus in evolution. J. Clin. Gastroenterol., 5: 335-338.

Rohde, H., H. Troidl and M. Fischer, 1975. Antral duodenal fistula following penetration and perforation of a prepyloric ulcer into the duodenal bulb. Gastrointest. Endosc., 22: 99-101.
Safatle-Ribeiro, A.V., U. Ribeiro Jr., A. Habr-Gama and J.J. Gama-Rodrigues, 1999. Double pylorus: Case report and review of the literature. Rev. Hosp. Clin. Fac. Med. Sao Paulo., 54: 131-134.

Smith, V.M. and K.W. Tuttle, 1969. Gastroduodenal (pyloric) band. Gastroenterology, 56: 331-336. 